\title{
Erratum to: Gastric Bypass Increases Ethanol and Water Consumption in Diet-Induced Obese Rats
}

\author{
Panayotis K. Thanos • Mike Subrize • Foteini Delis • \\ Robert N. Cooney • Derek Culnan • Mingjie Sun • \\ Gene-Jack Wang • Nora D. Volkow • Andras Hajnal
}

Published online: 15 December 2012

(C) Springer Science+Business Media New York 2012

\section{Erratum to: Obes Surg}

DOI 10.1007/s11695-012-0749-2

In the original publication, the institutional affiliation for fourth, sixth, and ninth authors appears erroneously as Pennsylvania State University, State College, PA. The correct institution is Pennsylvania State University College of Medicine, Hershey, PA.

The online version of the original article can be found at http:// dx.doi.org/10.1007/s11695-012-0749-2.

P. K. Thanos $(\bowtie) \cdot$ N. D. Volkow

Laboratory of Neuroimaging, NIAAA Intramural Program, NIH,

Bethesda, MD, USA

e-mail: thanos@bnl.gov

P. K. Thanos $\cdot$ M. Subrize $\cdot$ F. Delis $\cdot$ G.-J. Wang

Behavioral Neuropharmacology and Neuroimaging Lab, Brookhaven National Laboratory,

Upton, NY, USA

M. Sun $\cdot$ A. Hajnal

Department of Neural and Behavioral Sciences,

Pennsylvania State University,

University Park, PA, USA

D. Culnan

Department of Surgery, Pennsylvania State University,

University Park, PA, USA

R. N. Cooney $\cdot$ M. Sun $\cdot$ A. Hajnal

Department of Surgery, Pennsylvania State University

College of Medicine, Hershey, PA, USA

Present Address:

R. N. Cooney

Department of Surgery, SUNY Upstate Medical University,

Syracuse, NY, USA 